Available online @ https://jiem.jnnce.ac.in https:www.doi.org/10.37314/JJEM.2021.050208 Indexed in International Scientific Indexing (ISI)

\title{
Role of Management Practices in Apparel Company-A Case Study analysis
}

\author{
Jyothi G H' $\quad$ Veershetty G Rathod ${ }^{2}$ \\ ${ }^{1}$ Research Scholar and Assistant Professor, \\ PGDMS \& RC, PESITM, Shivamogga- 577204 \\ ${ }^{2}$ Assistant Professor, Department of Commerce and Management, \\ Sahyadri Commerce \& Management College, Shivamogga. 577203 \\ jyothiguntnur@gmail.com,jyothigh@pestrust.edu.in
}

\begin{abstract}
For any established company for his or her property growth, the implication of management ideas is additionally vital. The qualitative aspects of environmental factors should be thought-about for structure success. The study focuses on the problems regarding the attire company of recent Zeeland, which had started a number of years gone and strived to deliver the products to their customers at low costs. Completely different ways and implications of management ideas to succeed in the international customers supported the historical read mentioned.
\end{abstract}

Keywords: Lean Management, Pricing, Segmentation, Niche Market

\section{Introduction}

The research paper is about the study about Apparel Company of New Zeeland. The success of the company depends on many qualitative and quantitative factors. The research paper suggests the company to adopt and improve the operation methods, Management practices, Lean Management tools, Technology, Quality management techniques and Operation Strategy. So, then cost to the company, production and supply process will become efficient.

\section{Review of operation method and analysis of the applying of lean management principles.}

Lean describes a system that produces what the client desires, and after they wish it, with minimum waste. Lean producing could be a management philosophy that focuses on incessantly raising all the processes concerned in an exceedingly producing firm, regardless of what variety of product area unit being created.

The following lean management philosophy practices area unit appropriate for adoption [1].

- Overproduction - producing products quite the client's demands can increase the production, storage, and wastage price, Shoes should be factory-made by considering the demand.

- Waiting - Waiting implies watching for material, info, equipment, tools, etc. wherever the waiting time will be reduced.

- Transportation - Carrying of labor in method (WIP) for long-distance, shy transport, and moving material from one place to a different place is termed because of the uncalled-for transport. Finding staple in surroundings is healthier to cut back the transportation price.

- Over process - engaged on a product quite the particular necessities is termed as over 
process. This may consume longer and more resources. Excess Inventory -This includes excess staple, add method, finished product, devolution, broken product, transportation, and storage prices.

- Defects - Defects within the processed elements are understood as waste. Repairing of the defective elements, and manufacturing defective elements, or substituting the elements because of their lower quality, etc. is that a waste of effort and time. The method of quality management and effectiveness ought to be maintained.

- Excess Motion - uncalled-for motion is caused by poor advancement, housework, poor layout, and inconsistent or unregistered work ways. Worth stream mapping is additionally wont to determine this sort of waste.

- Underutilized folks - It includes underutilization of the mental, creative, and physical skills and talents. Staff ought to be skilled labors and Machines will be wont to increase the productivity and potency.

\subsection{Principles have to be compelled to be followed in Lean Implementation}

The initial step for implementing the lean conception in Shoes producing company is to outline the worth from the attitude of the ultimate client first. Then determine the worth stream by making a map of the present State and therefore the future State of the worth stream. $^{2}$ Distinctive and categorizing waste within the Current State, and eliminating it. Eliminating this waste ensures the provision of quality products to the client with no interruption, detour, or waiting. Come back to the primary step and start the subsequent lean transformation, giving a product that's ever additional nearly what the client desires.

\subsection{Lean producing Tools}

- 5S: 5S it's a way for systematic organizing and standardizing the geographical point. It's one of all the best Lean tools to implement within the business.
- TPM: it's necessary for the sleek functioning of production and offers the optimum utilization of machines with the least destruction of production.

- CM: CM is AN integral part of lean producing systems. It's primarily based upon the principles of cluster Technology.

- VSM: VSM is employed to seek out waste within the worth stream of a product. Once the waste is known, then it's easier to form arrange to eliminate it.

- KAIZEN: a method wherever workers work along proactively to attain regular, progressive enhancements within the producing method.

- Pareto Chart: The sociologist|economist|economic expert \} diagram could be a graphical summary of the method issues, in ranking order from the foremost frequent, all the way down to the smallest amount frequent, in descendent order from left to right.

- POKA YOKE: style error detection and interference into production processes to attain zero defects. This technique builds positive that the operator doesn't make any mistake whereas operating.

- KANBAN: Japanese word it means that instruction card. It will be any visual indication applied to order the need of half or part. It's a manual pull device that enables AN economical means that to transfer half from one search to the alternative.

- SMED: It focuses on simplifying machine setups. Scale back setup or transmutation time to but ten minutes, and it focuses on increasing production flexibility.

- JIT: Offering elements through production supported the client demand rather than pushing elements in production supported projected demand. It combines the proper things of the proper quality and amount within the right place at the proper time

- Visual Inspection: Makes the state and condition of producing processes simply accessible and really clear - to everybody. 


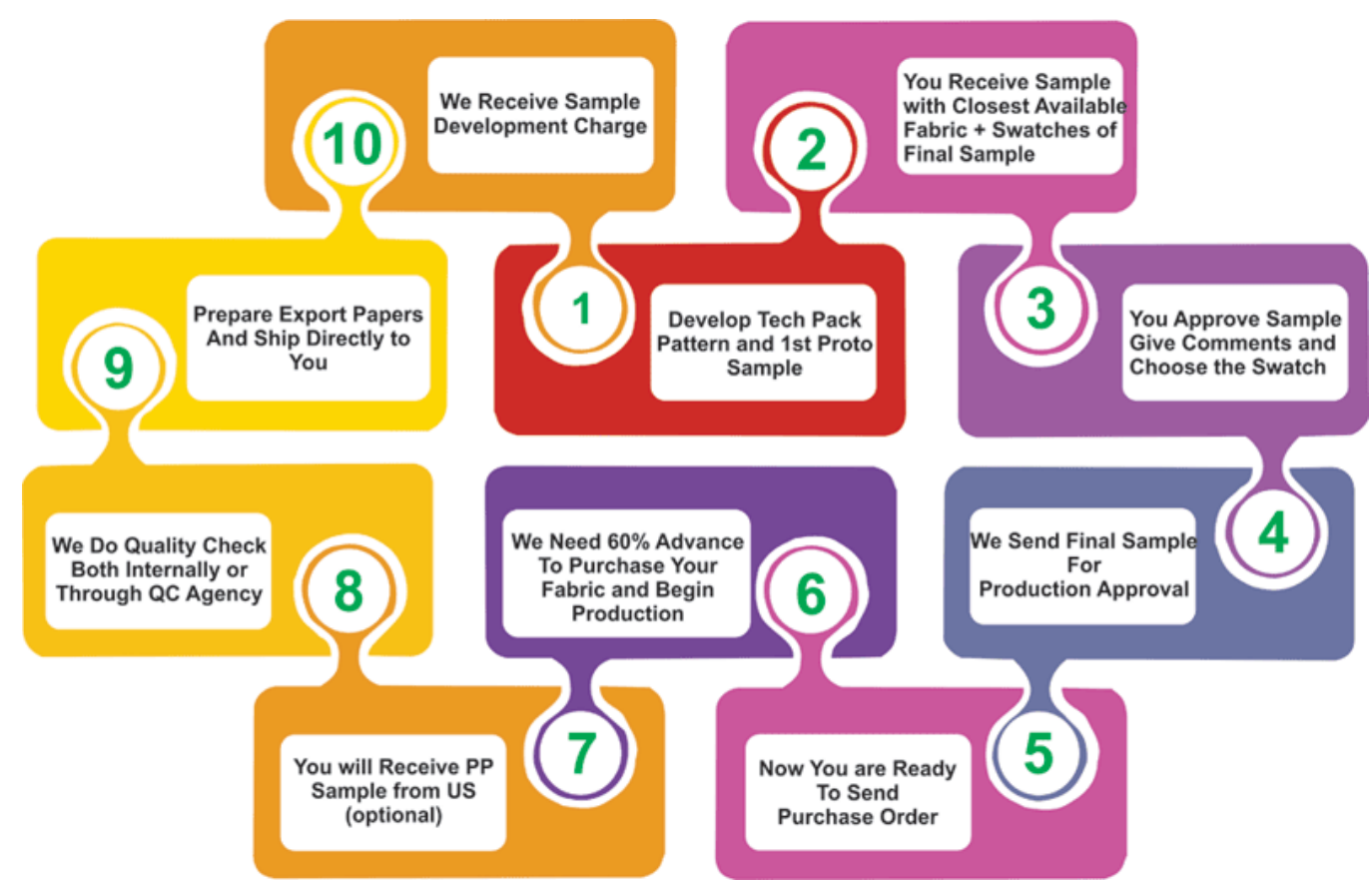

Figure 1: Lean Production Mechanisms in Apparel Company

(Source: https://textilelearner.net/lean-management-in-apparel-industry/)

Figure 1 shows the lean production mechanisms in an apparel company. The entire work will be narrowed to various smaller agencies wherever it's easier to supervise each task being performed and therefore the presence of multiple agencies ensures that point and capital area units are spent expeditiously. Once it involves trafficker choice, follows a strict and rigorous screening method to make sure that the standard of raw materials is apt and is provided in lesser time. With the vendors by qualifying them for future contracts, provided the seller systematically maintains constant potency within the production processes.

\section{Integration of adjusting business wants and key management components in technology in operation model}

- Business-technology strategy: Developing an Associate in nursing overarching business strategy will be difficult as a result of it needs leaders to create tough selections concerning the way to contend and win.

- Technology ambition: though each organization's context is totally different, in expertise, technology will primarily deliver price in six ways in which. Strategy: grade technology to directly form a business strategy, mission, and vision by making or enhancing products and services and delivering competitive advantage.

- Data: Leverage information across the enterprise to achieve the insight and connect info in operational, product, and digital technologies and disciplines.

- Agility: specialize in speed to marketfeaturing quicker, unvarying delivery through progressive technology investments.

- Customer: Emphasize client, product, and market impact and seamless client expertise.

- Automation: automatize business operations, processes, infrastructure, and applications.

- Business of IT: Deliver reliable, resilient technology environments; guarantee the flow of data for effective decisions; manage talent sources, ecosystems, and partners; and increase come back on technology investments. 


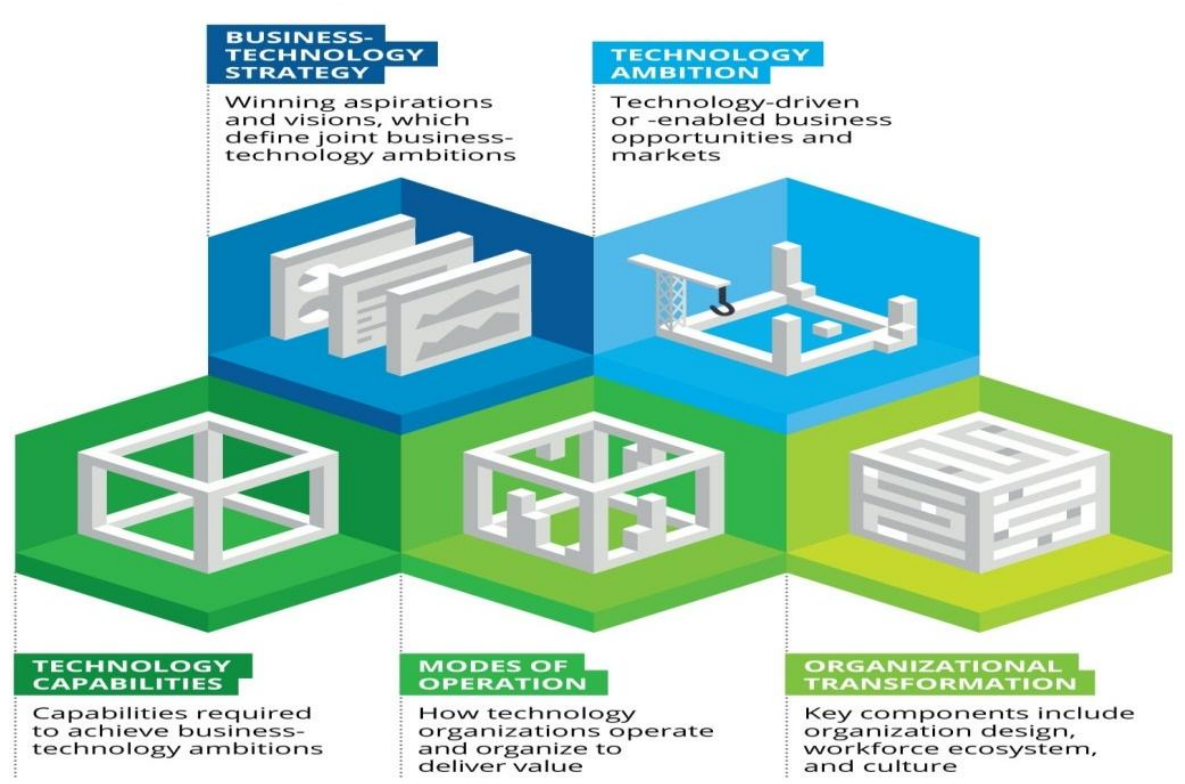

Figure 2: New Technologies Operating Model (Source: https://www2.deloitte.com/us/en/insights/)

Figure 2 shows the new technologies operating model. When technology organizations acknowledge that networks will exist internally, in business functions, and in broader business and technology ecosystems, they will build multidisciplinary groups, communities, coverage relationships, and communication channels that support natural human interactions. These cross-functional groups and relationships will establish direction, missions, and price statements that align directly with the organization's overarching strategy. ${ }^{3}$ this could change even the most important international organizations to work with lightsomeness and a mission-and-value orientation.

Although some businesses tackle structure style because of the commencement within the in operation mode design method, we tend to advocate taking it on toward the tip of the method. Encourage virtual, fluid, cooperative team structures instead of static, solid-line relationships

\subsection{Operation Technology Model}

As customers' real lives become more and more tangled with the digital world, several designers and makes should embrace the most recent technologies to push the bounds of producing, production, selling, and wear ability. ${ }^{4}$ From the most recent in AI to the boom of mobile commerce, 3D printing, and block chain, we've rounded a number of the highest school advancements getting used in fashion nowadays.

\subsubsection{Artificial intelligence}

In recent years, brands are victimization AI to boost customers' searching expertise, analyse information, boost sales, forecast trends and provide inventory-related steering.

- FINERY. A people fashion label has come back up with an automatic wardrobe coming up with a tool that, victimization analytics, records its feminine customers' purchases and introduces them in a very virtual wardrobe. The platform conjointly permits girls to make an appearance from their wardrobe and even make a choice from over ten,000 shops.

- The personalization platform TRUE FIT employs an internet match engine that helps users realize Associate in nursing adequate match with brands and new designs on the market. 
- Edited, an organization based mostly in London, provides live information analytics code to relinquish their merchant customers access to complete market information instantly.

- Intelligence Node, which permits users to trace trends in the period. Customers will enter specific keywords, user navigation patterns, worth points, and additional.

\subsubsection{Novel materials}

Area unit arguably the long run of fashion, as otherwise within which designers will set them apart and charm as a property choice.

\subsubsection{Web of things (IoT)}

The IoT describes a network of objects - the 'things' - that area unit embedded with technology to permit the exchange and association of knowledge over the web. This is often one of the foremost exciting, rising technological trends within the fashion market. Year-on-year, everyday fashion continues to enhance to mirror the realities of our daily lives. From excellent stress on comfort to victimization of new and exciting materials, the fashion business has had to stay up the pace in adapting to the stress of up to date life. ${ }^{5}$ this has been seen most clearly within the exciting advancements in attire technology and wearable gadgets. These have gone as so much as poignant however we tend to expertise our surroundings, move with others and our bodies, giving the word comfort a full new that means.

\subsection{Ever-changing Business Need}

Streaming live videos has become an enormous part of our lives. From virtual events to fitness, Instagram searching has taken 2021's post-COVID market. 5G permits new streaming media formats with high-definition graphics. Now, customers will "try on designs" before creating their purchases. Some brands, area units give digital showrooms to measure the market's appetence. Some enable customers to pre-order digital styles before they are going into production. Likewise, several online-only eyewear firms like Firmoo and Glasses Direct also are giving a digital 'try-before-you-buy service that lets customers visualize the frames on their faces before committing.

Historically, trend prognostication exclusively relied on previous trends to predict the long run. New technologies like Heuristic outline audience panels on social media. To predict future trends, it applies image recognition technology to social media photos to access shapes, prints, colors and attributes to materials.

Google conjointly deployed the same experiment, in partnership with German fashion complete Zalando. ${ }^{6}$ The neural network was trained to know vogue preferences, colors, and textures. After that, the algorithmic program was accustomed produce styles that supported users' designs preferences. There's conjointly the cooperative project between IBM and also the Fashion Institute of Technology referred to as "Reimagine Retail" that uses the hi-tech IBM AI tools to point period industry trends, themes in trending shapes, colors, and designs. These technologies highlight however AI is that the bastion of future developments within the industry, shaping everything from trend prognostication to however customers may very well see and purchase products.

\section{Quality Management System}

Figure 3 shows the quality management system process in an apparel company. 


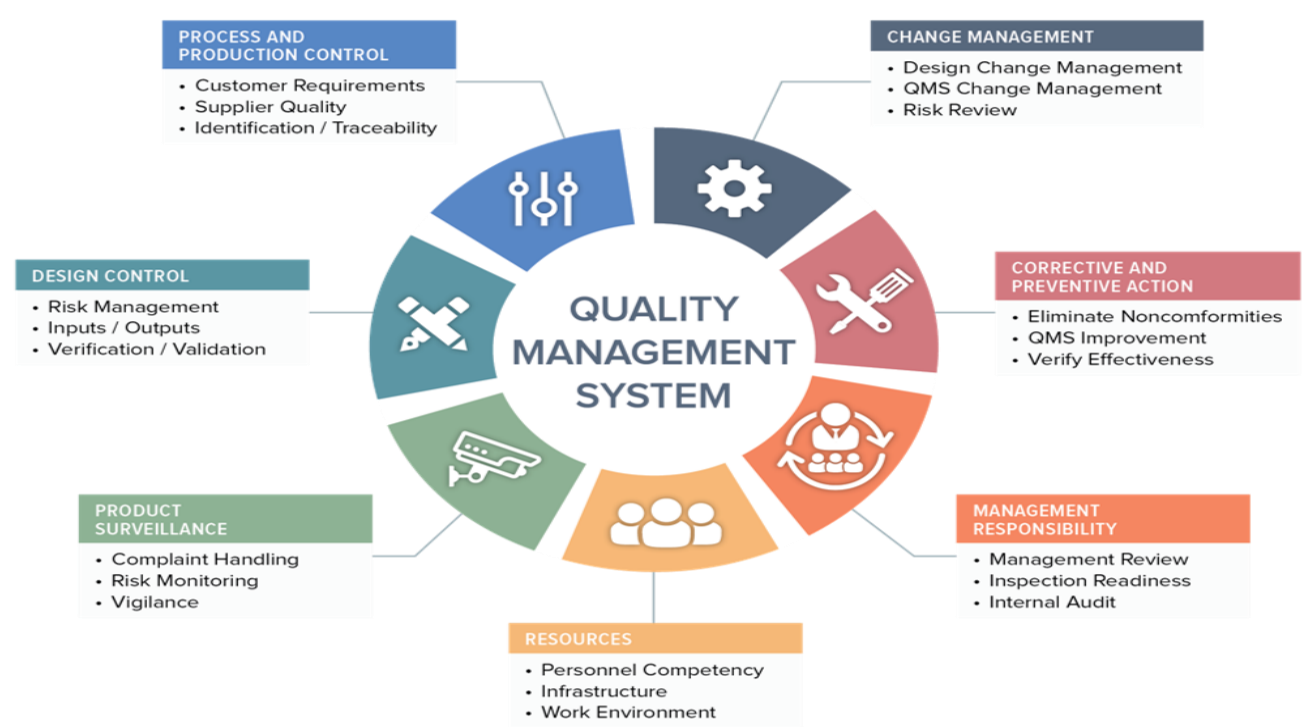

Figure 3: Quality Management System Process in Apparel Company

(Source:https://www.orielstat.com/blog/medical-device-qms-overview/)

\subsection{Quality Control Mechanism}

\section{- Inspection}

Inspection is often outlined, within the fashion industry, because the visual examination or review of raw materials (such as cloth, Buttons, Zippers, stitching threads, Trims, etc.), partly finished elements of clothes the clothes $\}$ and utterly finished garments in reference to some standards, specifications or needs, additionally as mensuration the clothes if they meet the desired measurements.

Figure 4 shows the process of quality control.

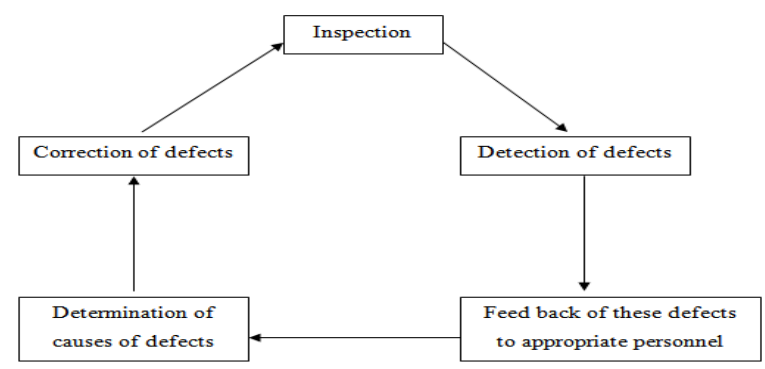

Figure 4: Process of quality control

(Source:https://textilelearner.net/basic-concept-ofquality-in-apparel-industry/)

In the clothes trade, the required or expected quality parameters are controlled by examination. This examination is often exhausted in 3 steps: i. Material examination in trade

ii. In method examination in trade

iii. Final examination in trade

\section{- Quality Philosophy and client desires}

Figure 5 shows the customer desire.

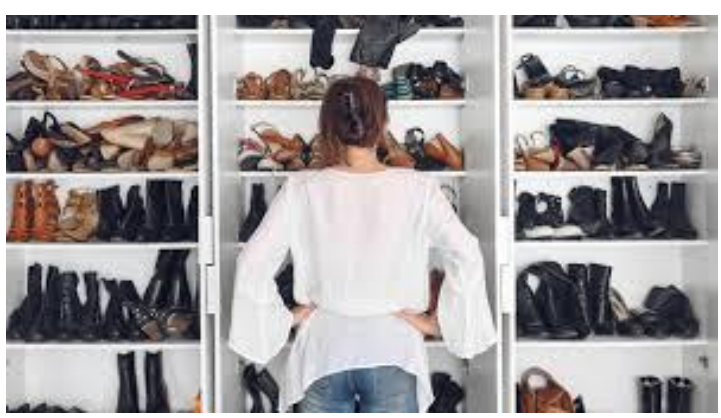

Figure5: Customer desire

(Source: https://www.businessinsider.in/thelife/)

Recognize direct and indirect customers as those that receive worth from the organization.

$\checkmark$ Perceive customers' current and future desires and expectations.

$\checkmark$ Link the organization's objectives to client desires and expectations.

$\checkmark$ Communicate client desires and expectations throughout the organization. 
$\checkmark$ Plan, design, develop, produce, deliver and support merchandise and services to fulfill client desires and expectations.

$\checkmark$ Live and monitor client satisfaction and take acceptable actions.

$\checkmark$ Confirm and take actions on interested parties desires and expectations which will have an effect on client satisfaction.

Actively manage relationships with customers to realize sustained success.

\section{- Maintaining Quality Philosophy with Customers and Application}

Customer's Quality needs have to be compelled to be identified; completely different styles of Shoes ought to be made to fulfil the multiple functions. the Merchandise ought to be offered at a cheap value. Accessibility of the products for the customer's inconvenience.

The analysis department ought to conduct marketing research and survey to grasp the purchaser's opinion. Trade analysis can facilitate to make a competitive edge to become a lead company. Client relationship management activities follow up, and response system ought to exist to handle the client grievances. Correct provide chain management within the company can scale back the cost; online platforms are often used to build the method easier and convenient. ${ }^{7}$

\subsection{Code employed in the fashion business}

\section{- Cegid}

Cegid provides cloud-based retail code to fashion and luxury, beauty, additionally as specialty retailers. The system is constructed on one, centralized info that's shared across all channels and updated in real-time with client information, products, prices, and sales. On-premise readying is additionally out there and Cegid is compatible with Windows in operating systems. additionally, to its location (POS) module, Cegid additionally offers: Omnichannel order management; Reserve on-line, obtain In-store; obtain on-line, Pickup In-Store (BOPIS); Order In-Store, Ship from Anywhere; Ship-fromStore; correct inventory visibility; Digital and mobile POS solutions; and CRM.

\section{- SnapFulfil WMS}

SnapFulfil could be a cloud-based warehouse management resolution (WMS) appropriate for a spread of industries as well as B2B and B2C retail, 3PL, producing food and beverages, and natural philosophy. Key options embrace receiving, put-away, inventory management, picking, dispatching, and reportage. SnapFulfil offers an area utilization feature that permits storage planners to style and implement floor plans with the most storage. The route improvement feature permits managers to set up the shortest routes for the delivery trucks. It additionally supports Parcel Labelling that helps in the trailing movement of things across the provision chain. SnapFulfil supports multiple choosing methodologies as well as multi-zone, wave, decide and pass and additional.

\section{- ChainDrive}

ChainDrive is associate omni-channel retail management resolution designed for retailers, e-tailers, and wholesalers. The answer is intended for attire, footwear, sports equipment, jewellery, home goods, and retail store and specialty retailers. Key options embrace web-order fulfillment, CRM, inventory management, commercialism, warehouse management, the purpose of sale and monetary management. Chain Drive offers client relationship management (CRM) options that facilitate retailers to capture all client connection information so style targeted offers to drive loyalty. The answer provides analytics and reportage options that permit users to spot that merchandise to push.

\section{- iRetail}

iRetail is an associate on-premise retail resolution for larger retailers with quite ten locations. It targets department shops, supermarkets, specialty stores, warehouse stores, lifestyle/ attire chains and fast service 
restaurants. Primary options embrace merchandise trailing and management, promotions, client loyalty programs and whole campaign creation supported client, store, class and whole. Different options embrace the purpose of sale (POS), inventory management, client management, retail accounting, e-commerce and warehouse management. The client management application permits users to make client info as well as getting and payment histories.

\section{- ACCEO Retail-1}

ACCEO Retail-1 could be a complete Omni channel code suite designed and developed for today's fashionable merchandiser.
Users will seamlessly manage and manage all aspects of their Omni channel retail business with one package that integrates in-store, e-commerce, and every one head-office operation. The Retail-1 end-to-end code suite consists of complete front and back-end management with key options that include; the purpose of sale, CRM, commercialism, inventory and order management, open-to-buy, markdown management, warehouse management-commerce, business intelligence and additional. Its distinctive options and functions are specifically developed to adapt to a number of the foremost complicated retail environments.

\subsection{SAP Process}

SAP design of an apparel company is shown in figure 6 .

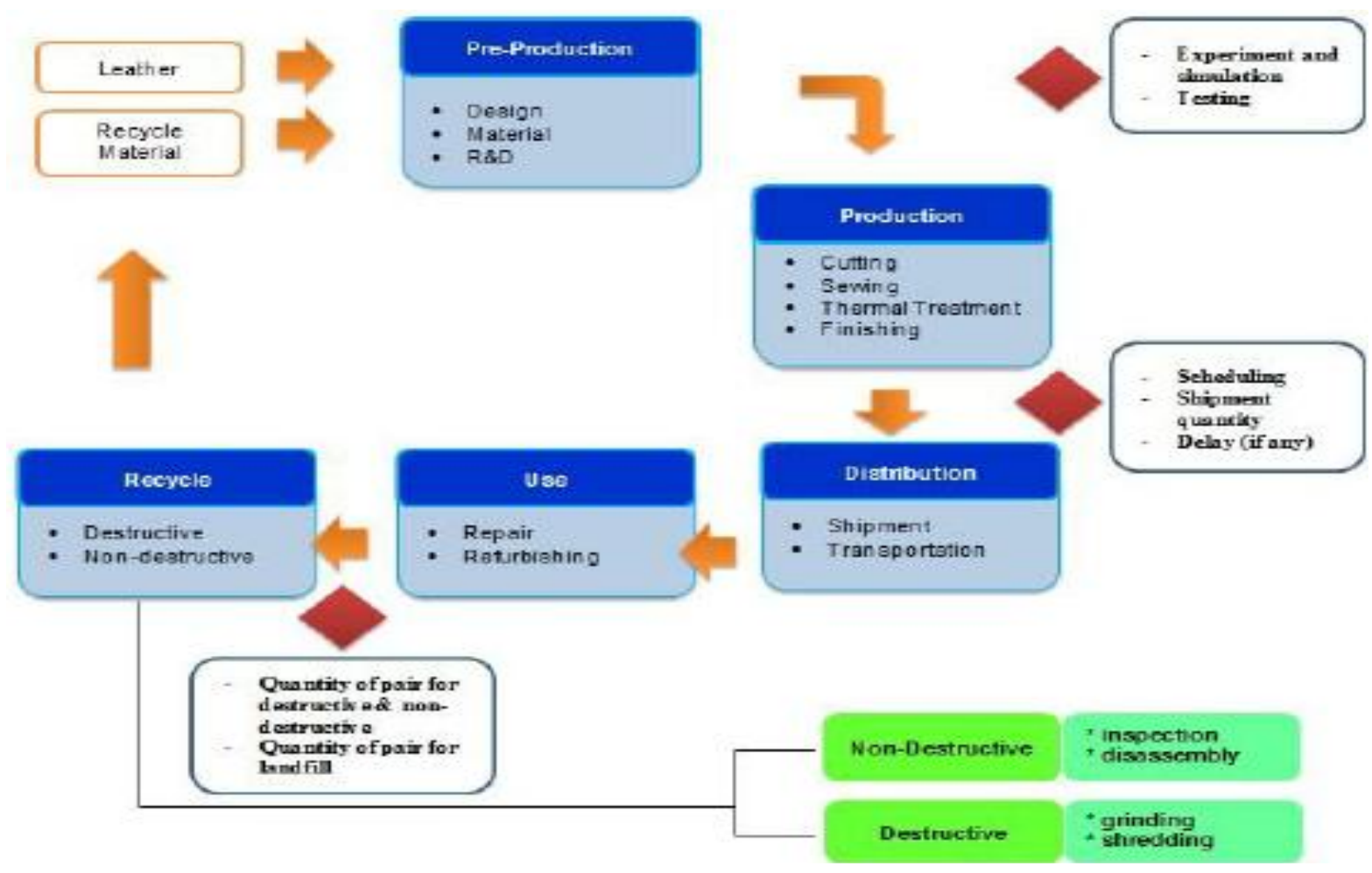

Figure No: 6 SAP design of Apparel Company

(Source: https://www.savictech.com/savic-fashion.php) 


\section{Operation Strategy}

The organization ought to establish the structure desires and client desires. The organization ought to embody the competitive strategy which has the value leadership and products differentiation strategy.

Keep lower price for analysis and production for competitive advantage. Organization should focus a lot of on streamlining and increase their quality of production. This objective is to form positive that the system is economical. Product Focus strategy, maintained high production and low style of product, will facilitate to scale back variable price and enhance potency. Even if they manufacture many product classes, all of its product share most of the materials, technologies and style model. To stay differentiation, it focuses on short-run analysis product \} development since it'll introduce new products quick and hamper the payback amount.

Strategic plans will improve the revenues and reach of Footwear Company through production, expansion, disapproval or style ways. If the corporate manufacture, import and distribute shoes, or simply retail shoes within the us, outline the target market and concentrate on penetration, development, market development and diversification.

\section{- Compete Through Innovation}

To vie against established footwear brands or retailers is in penetration strategy, and one in all the primary components of the strategic arrange. Nike chief executive officer Mark Parker had a goal of exploitation product innovation and technology to inspire shoppers -- whether they were active or simply aspiring athletes. Vans, a long-time active wear company, cantered on changing into a part of the skateboard and extreme sports culture by sponsoring athletes and events like surfriding and skating contests. Every footwear company achieved penetration by increasing its strengths. Nike cantered on innovative technology and Vans cantered on redesigning its basic shoes to suit with the niche skateboard and surfriding cultures. Take into account however organization strengths compare with competition and make strategy to emphasize what to try and do best.

\section{- Create New Standout Product Lines}

Make own product stand out from the overall marketplace if the corporate desires to regulate footwear niche. Develop future product models supported what created originals distinctive. Ugg entered the footwear market with a wholly vogue and fittingly named the corporate Ugg to suit its basic, primitive-style shearing boots. The design and name created the merchandise stand out, however it absolutely was the comfort and heat of the boots that developed fans. Once the first boots had caught on within the marketplace, the corporate branched into different footwear offerings like shearling-lined clogs and flats, pleasing previous fans and attracting new customers. Nike developed new shoe-construction technology to guide the athletic shoe market, and often introduced exciting new models at high costs for the first adopters, permitting older models to visit value to charm to their thought shoppers.

\section{- Expand the Scope of Marketplace}

Markets developed will typically be duplicated overseas via net promoting and e-commerce applications on website, like looking carts and content translation. Most major brands in footwear have developed their market reach on the far side shores. Sometimes, a modest whole will become a lot of fashionable offshore customers, significantly if it's a powerful charm of favor and culture. The strategy behind developing markets is to avoid obtaining caught in fashion changes or economic downturns in own country, and to unfold operative risk over many sovereign economies and cultures once possible. 


\section{- Diversify to scale back Risk}

Along with spreading risk by developing offshore markets, It may also unfold product risk by developing completely different product lines like article of clothing, sports and travel accessories. Nike may be an exemplar of an organization that has gone from Associate in nursing athletic shoe company to Associate in nursing athletic mode company through article of clothing, accessories and sporting goods.

\section{References}

1. Rashmi Kumari1 , T. Z. Quazi and Rishi Kumar, Application of Lean Manufacturing Tools in Garment Industry, International Journal of Mechanical Engineering and Information Technology, Vol.3, Issue 1, 2015, pp. 976-982.

2. Md. Mazedul Islam, Adnan Maroof Khan, and Md. Monirul Islam, Application of Lean Manufacturing to Higher Productivity in the Apparel Industry in Bangladesh, International Journal of Scientific \& Engineering Research, Volume 4, Issue 2,2013.
3. Linden, Annie Radner, An Analysis of the Fast Fashion Industry, Senior Projects Fall 2016.30.

https://digitalcommons.bard.edu/senproj_f2016 130

4. Wonsoek Choi, Nancy B Powell and Nancy L Cassill, New Product Development and its applications in Textiles, Journal of Textile and Apparel, Technology and Management, Vol. 4, Issue 4, 2005.

5. Tatiana Destiny Sitaro (2020), Fast Fashion and Sustainability - The Case of Inditex-Zara, Digital Research@Fordham.

6. Sumera Ahmad, Suraya Miskon, Rana Alabdan, Iskandar Tlili, Towards Sustainable Textile and Apparel Industry: Exploring the Role of Business Intelligence Systems in the Era of Industry 4.0, Sustainability, 2020, pp.1-23.

7. Ramune Ciarniene and MIlita Vienazindiene, Management of contemporary fashion industry: characteristics and challenges, Procedia - Social and Behavioral Sciences Vol.156, 2014, pp. 63 - 68. 